\title{
Radical Transformation of Universities to Prepare the Next Generation of Climate Champions
}

\author{
Irena F. Creed, Meghna Ramaswamy, Matthew Wolsfeld, Stryker Calvez, \\ Murray Fulton, Karsten Liber, Darcy D. Marciniuk, Jacqueline Ottman, \\ Nancy Turner, Laura Zink, Erin Akins, Kevin Hudson, Jamie Bell, \\ Autumn LaRose-Smith, and Jory McKay
}

\begin{abstract}
The threat and reality of climate change must be acted upon individually and collectively. Universities have a decisive role to play in this regard - by creating the capacity in all its academic activities to lead in taking on the challenge and by graduating students with the capacity to solve the problems that the climate change situation poses. To take on these roles, universities must accept a "radical transformation". Radical transformation is a process that requires two integrated activities: radical thinking and transformative action. We propose that it is radical to think of universities as microcosms of society; that is, universities face the same need as everyone else to find ways to mitigate and adapt to climate change. We also propose that it is transformative for universities to inspire and be agents of change for the world: by creatively developing strategies to mitigate and adapt to climate change, universities can become global leaders in demonstrating workable solutions capable of being broadly diffused and scaled up. We present a set of design aspirations that can help universities undergo a radical transformation and thereby make headway in addressing the climate crisis.
\end{abstract}

\section{Keywords}

design aspirations - living laboratory - diverse learners - innovation ecosystems public engagement

\section{Introduction}

It is increasingly important that universities dedicate themselves to solving the most pressing issues facing the planet (Crow \& Dabars, 2020). Universities 
have a social responsibility to become what the world needs. These needs are well articulated in the United Nations' Sustainable Development Goals (SDG) framework, consisting of 17 SDG s, 169 "targets", and 223 "indicators" adopted by 193 member states in 2015. These markers are a universal call to action to end poverty, protect the planet, and ensure that all people enjoy peace and prosperity (United Nations, n.d.).

One SDG requires immediate focus - SDG 13, Climate Action. Climate change is occurring at a rate much faster than anticipated, and accelerated action is needed on climate mitigation and adaptation to stay within planetary boundaries (Rockström et al., 2009). The scientific consensus is that the earth's climate has warmed significantly since the late 1800 , that human activities are the primary cause, and that continuing greenhouse gas emissions will increase the likelihood and severity of global adverse effects. What is needed is for people and nations to act individually and collectively to slow the pace of global warming (mitigation) while also preparing for unavoidable climate change and its consequences (adaptation) (Ripple et al., 2020). Governments, industries, and societies need to make rapid and systemic changes as to how climate change is addressed (Ripple et al., 2020). This injunction is particularly vital, since the other SDGs cannot be achieved, or ultimately sustained, unless the earth's climate system is stabilized (Stechow et al., 2016; Fuso et al., 2019; Keys et al., 2019).

Universities will be essential in shaping the way people think and feel about climate change and act to address it. Collective knowledge, with all of its diversity, along with holistic approaches to the creation of tools to understand and solve complex problems, will be needed to achieve climate change mitigation and adaptation. As motivating centers of teaching, learning, discovery, innovation, and entrepreneurial activities, universities can be an engine of transformation by finding ways to stabilize the world's climate and by supporting the local and regional transitions that are needed.

The University Plan 2025 commits our university, the University of Saskatchewan, to being "the university the world needs". We have set out a bold vision to harness our talents and resources to respond to contemporary challenges and opportunities. To fulfill this vision, we are placing high priority on sustainability and on the UN SDGs. Only by addressing the interlinked social, economic, and environmental challenges captured by the SDGS will it be possible to tackle climate change and protect the planet and at the same time to create a prosperous, just, and equitable society. We recognize that sustainability is not merely another problem to be tackled or solved. It needs, rather, to pervade all decisions within our institution. It requires transformations in the very DNA of our institution. With only 10 years remaining before the UN 2030 Agenda for Sustainable Development deadline, the time to act is now. Over the past year, members of the university community - administrators, faculty, 
staff, students - came together to identify the many initiatives already under way on campus, to scope out areas of improvement or areas where actions are needed, and to forge ahead with a cohesive strategy that defines our critical paths to sustainability. Here, we present our plan for climate action.

Universities are motivating centers of teaching, learning, discovery, innovation, and entrepreneurial activities. As engines of transformation, universities can deliver on actions needed to stabilize the world's climate and drive local and regional transitions to a just and sustainable future. However, the actions needed to address climate change will require a radical transformation, a process that requires two integrated activities, (a) radical thinking, and (b) transformative action.

As a starting point for a radical transformation, we propose that it is radical to think of universities as microcosms (from the Greek mikros kosmos, or "little world") of society. Although universities are typically thought of as elite institutions and ivory towers cut off from the rest of society, in actuality they are microcosms of society. They are complex organisms, inhabited by highly diverse individuals and organizations, with their own cultures, languages, norms, and governance rules. They share the same problem as does the rest of society: the need for people and organizations to work together to find ways to mitigate and adapt to climate change. We also propose that universities must function as transformative entities meant not just to inspire but also to be positive agents of change for the world. A university's commitments to climate action must be designed to benefit not only its own community but also the communities beyond it, and to facilitate the rapid dissemination of climate-action expertise and experience.

Ambitious climate action requires climate knowledge to be incorporated into all levels and all aspects of the education system, including post-secondary education. Universities, at least in theory, are well placed to leverage the power of teaching, learning, and discovery and to leapfrog conventional action. Below, we present design aspirations universities can adopt to radically transform themselves to create the next generation of climate champions.

A vision for a new wave of universities is emerging, one that combines worldclass research enterprises with broad accessibility to learners - all to effect a 
shift in social outcomes toward equality and equity (Crow \& Dabars, 2020). This new wave reflects a radical transformation in which universities convene, facilitate, and mediate relevant and allied conversations related to the SDGS, advance teaching and research about the SDGs, and affect social outcomes that will help achieve the SDGs (Crow \& Dabars, 2020). The design aspirations for this new wave of universities (Crow \& Dabars, 2015) form the basis for the proposed radical transformation at the University of Saskatchewan. Here are summaries, and we further discuss each in subsequent sections.

- Leverage Our Place. Be responsive to the university's social, economic, environmental, and cultural settings, and influence and be influenced by them as solutions to climate-related problems are created, mobilized, and shared.

- Model the Way. Reduce the university's greenhouse gas emissions $45 \%$ from its 2010 levels by 2030 and achieve net-zero emissions by 2050 on campus.

- Empower Action. Support a generation of learners and achievers to shift mindsets and expand skill sets to accelerate climate action.

- Capitalize on Strengths. Bring together the campus community to generate new knowledge, with a focus on creating and implementing workable solutions to the various aspects of climate change.

- Catalyze Social Change. Share knowledge, expertise, and experiences to affect the response to climate change that is needed.

Taken together, these design aspirations outline a major shift for the university, a radical transformation in which it sees itself much more embedded in the society of which it is part and much more responsive to that society's needs.

The university's radical transformation will require responsive, flexible, and agile governance structures, starting with the university itself. See Figure 4.1 for a graphic depiction of a potential organizational structure (Walls, 2020). Applying the organizational framework to climate action, universities can be supported by a cluster of climate innovation teams in the areas of operations, teaching and learning, and discoveries, innovations, and entrepreneurship that can design and implement climate solutions for the university as well as for the city, region, and country to help the university achieve its commitment to climate action. Universities can also be supported by an external climate advisory table comprised of advisors, collaborators, and partners who will work alongside the university to achieve shared goals. For this external climate advisory table, special attention should be placed on the inclusion of Indigenous elders and knowledge keepers.

The university needs to become an open system (Ermine, 2007), in which the campus itself is viewed as an experientially driven classroom that daily, 


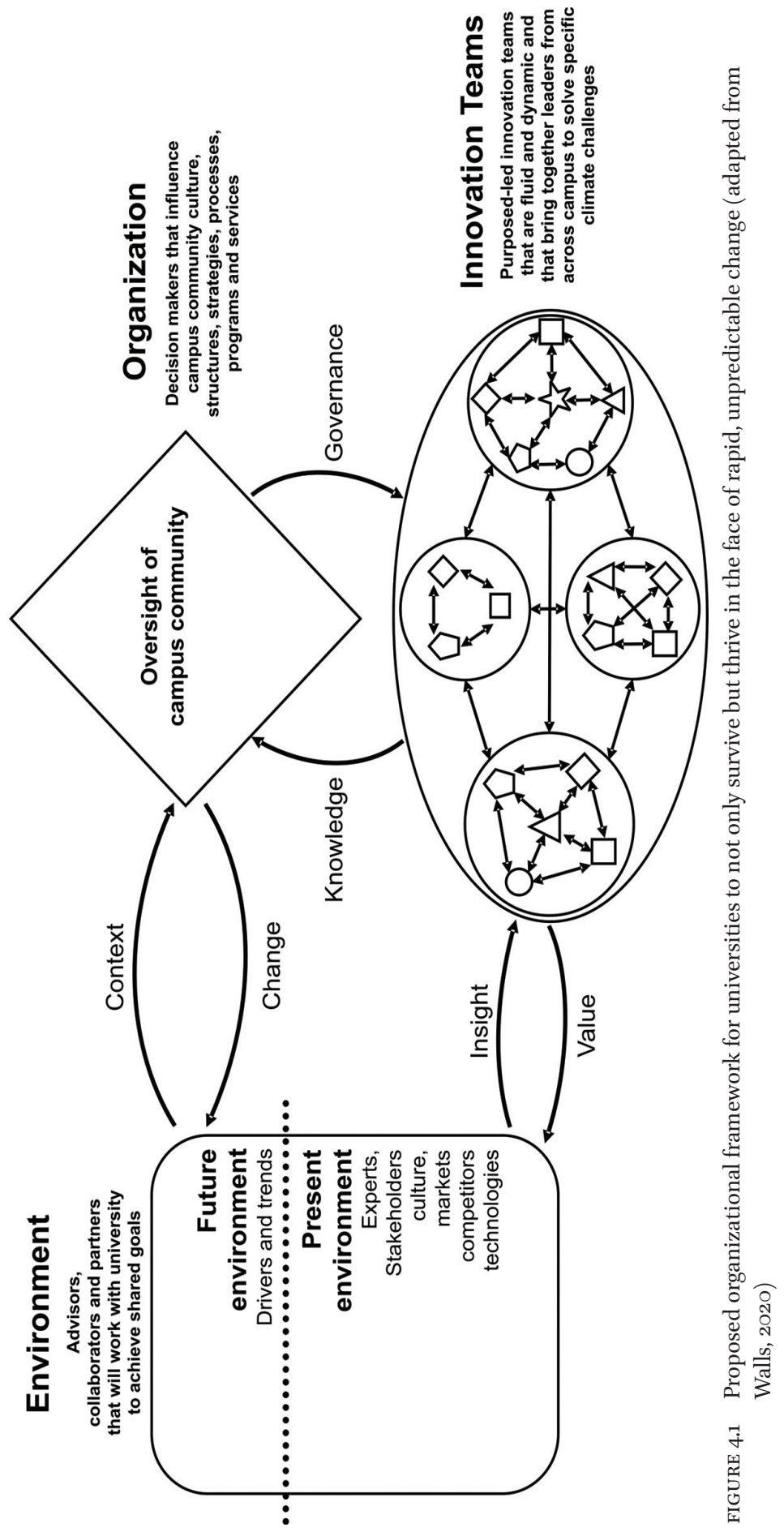


through organizational behavior, campus policies, procedures, and practices, and community engagement, incorporates responsible citizenship and environmental stewardship. Further, the university needs to foster an interconnected, creative, innovative, and entrepreneurial campus spirit, and to use its campus as a living laboratory, a place to pilot and perfect climate solutions, both those collaboratively and interprofessionally developed, and those requiring coordinated local, regional, and national efforts. Finally, the university needs to bind together - through equitable partnerships - the exuberance of youth and the wisdom of experience as people explore, discover, and find ways to implement new ideas. Youth are just as invested as older people, possibly more so, and have a right to influence decisions. In enlisting youth, we will help in building a generation of leaders more influential and more capable than those we have now.

\subsection{Design Aspiration: Leverage Our Place}

The need for swift and immediate action on the interconnected global impacts of climate change has led to an alignment of local, regional, national, and international agendas. At the 2015 UN Framework Convention on Climate Change (UNFCCC) Conference of the Parties (COP) 21 meeting, more than 170 countries (including Canada) adopted the Paris Agreement

to strengthen the global response to the threat of climate change by keeping a global temperature rise this century well below 2.0 degrees Celsius above pre-industrial levels and to pursue efforts to limit the temperature increase even further to 1.5 degrees Celsius. (United Nations, 2015)

World leaders agreed that meeting this goal of 1.5 degrees Celsius will require reducing our greenhouse gas emissions $45 \%$ from their 2010 level by 2030 and achieving net-zero emissions by 2050 (IPCC, 2018).

This push for action has seen broad support among Canadians. For example, during the 2019 Canadian federal election, $35 \%$ of Canadians listed climate change among their top three most pressing issues at the ballot box (Shah, 2019). Under the Paris Agreement, Canada committed to reducing its greenhouse gas emissions to $30 \%$ below 2005 levels by 2030. This change would require a national reduction of 218 metric tons $(\mathrm{Mt})$ of carbon dioxide equivalent $\left(\mathrm{CO}_{2}\right.$-eq) below 2018 emissions levels (Government of Canada, 2020). Canada has projected that its various economic sectors will contribute a reduction of $199 \mathrm{Mt} \mathrm{CO}_{2}$-eq, with additional projected emissions to come from offset credits, land sector contributions, and future reductions (such as clean electricity, greener buildings and communities, and electrification of transportation). 
Substantial efforts will be required if this target is to be achieved. Current projections by the Government of Canada still place our national emissions 77 $\mathrm{Mt} \mathrm{CO}_{2}$-eq short of its 2030 target (see Figure 4.2). In order for Canada to meet its national target, significant work will be needed in the following areas: clean energy sources; low-carbon transportation strategies; low-carbon building strategies; biodiversity; sustainable fisheries, forestry, and agriculture practices that limit greenhouse gas emissions and enhance carbon sequestration while protecting water resources; carbon pricing and other economic and policy incentives designed to promote and encourage these practices; and participatory governance institutions (Sustainable Canada Dialogues, 2015). This work will require the contributions of regional and municipal governments, Indigenous sovereign nations, industry, not-for-profits, and civil society (including, not least, universities).

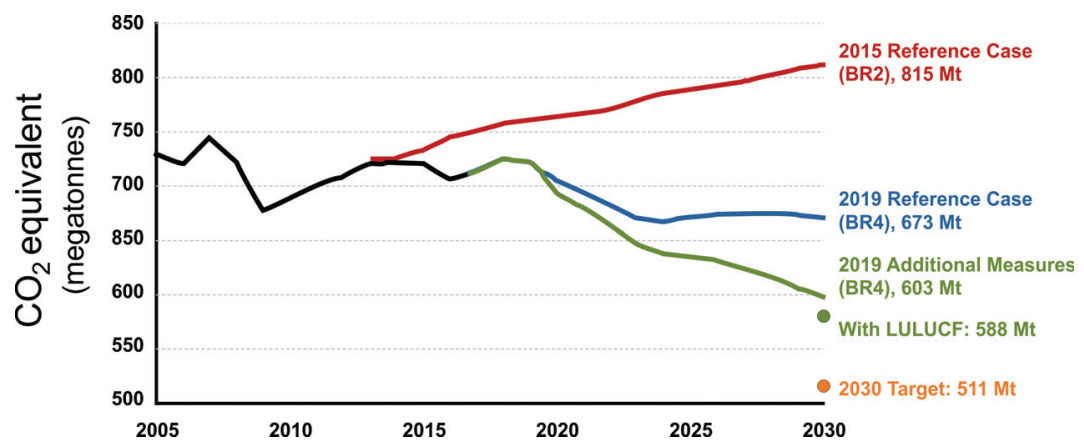

FIGURE 4.2 Historical greenhouse gas emissions and projections in Canada, 2005 to 2030. Historical data from 2005 to 2017 taken from the Government of Canada (2017)

As shown in Figure 4.2, future data include several projections including: (1) the 2015 Reference Case scenario that includes policies and measures in place as of September 2015; (2) the 2019 Reference Case scenario that includes policies and measures in place as of September 2019; and (3) the 2019 Additional Measures scenario that includes additional measures from Canada's clean growth and climate change plan that have been announced but are still under development (Government of Canada, 2019).

The Government of Saskatchewan has recently released its Growth Plan, which includes 30 goals for 2020-2030 (Government of Saskatchewan, 2020). Among these goals is a growth in population to 1.4 million people, 100,000 new jobs, and ambitious growth targets across sectors: private capital investment and the agriculture, oil, mining, and forestry industries. These goals will have profound impacts on the province's greenhouse gas emissions. At the same time, climate change will have profound impacts on these sectors. As 
an institutional leader in the province, the University of Saskatchewan can support the Government of Saskatchewan's Growth Plan while stressing the need for climate action. The university can gather influential voices and lead informed discussions for the purpose of coordinated climate actions. Much of the university's own success comes from working in a coordinated way with the City of Saskatoon and the Province of Saskatchewan, and these entities can benefit from working together to develop ways to mitigate and adapt to climate change.

The University of Saskatchewan commits to becoming more responsive and to influence, and be influenced by, our social, economic, environmental, and cultural settings so as to be better situated to create, mobilize, and share climate solutions. Our goal is to be an engaged university that works in a coordinated and innovative way with communities to develop climate solutions. To achieve this goal, we aim to:

- Establish a joint university-community advisory table to share, exchange, create, and identify synergies. The table will include representation from government, industry, not-for-profits, and all communities wanting to co-create and co-implement climate solutions for society.

- Nurture public discourse and convene public discussions on climate change with the goal of inspiring widespread climate awareness, engagement, and action.

- Build bridges and create portals through which external partners can easily and effectively engage with the university community as well as offer new perspectives and opportunities to together drive shared action on climate change.

\subsection{Design Aspiration: Model the Way}

The University of Saskatchewan faces the same need as everyone else to reduce greenhouse gas emissions - climate change is occurring at a rate much faster than anticipated, and accelerated action is needed to stay within the safe operating space for humanity (Rockström et al., 2009). Our strength lies in our ability to leverage the power of cutting- and leading-edge discoveries to do our part to support the local, regional, and national transitions that are needed for a more just, equitable, and sustainable future. In deploying our resources in service of our core mission - generating new and meaningful knowledge - we can serve as living laboratories for setting priorities and designing and implementing climate solutions that can be adopted and adapted elsewhere.

University greenhouse gas emissions fall into three categories, which we denominate and measure in "scopes" as follows: Scope 1, direct emissions produced from activities on property the university owns or controls (such as emissions resulting from heating with natural gas, running a fleet of vehicles, 
and conducting agricultural operations); Scope 2, specific indirect emissions produced by electricity the university consumes; and Scope 3, all other indirect emissions from sources not owned or controlled by the university. There is an emerging idea of Scope 4 emissions, which are emissions avoided by working in a coordinated way to lead (or to participate where others are leading) in developing strategies and in investing in projects and initiatives that align with regional, national, and international climate agreements.

The University of Saskatchewan began monitoring its greenhouse gas emissions in 2010, using a baseline of 2006/o7 emissions levels (Figure 4.3).

Since then, our total greenhouse gas emissions have not changed significantly, increasing by $6.4 \%$ to $171,299 \mathrm{Mt} \mathrm{CO}_{2}$-eq for the $2019 / 20$ fiscal year; however, building floor space has increased $21 \%$ since $2006 / 07$, resulting in a $14 \%$ reduction of emissions per square meter (also referred to as emissions intensity). In terms of the university's individual scope emissions over time:

- Scope 1 emissions have increased 8.4\% from the 2006/o7 baseline (as of $2019 / 20$ ) and currently make up $38 \%$ of the university's measured emissions. The majority of these emissions are from natural gas consumption

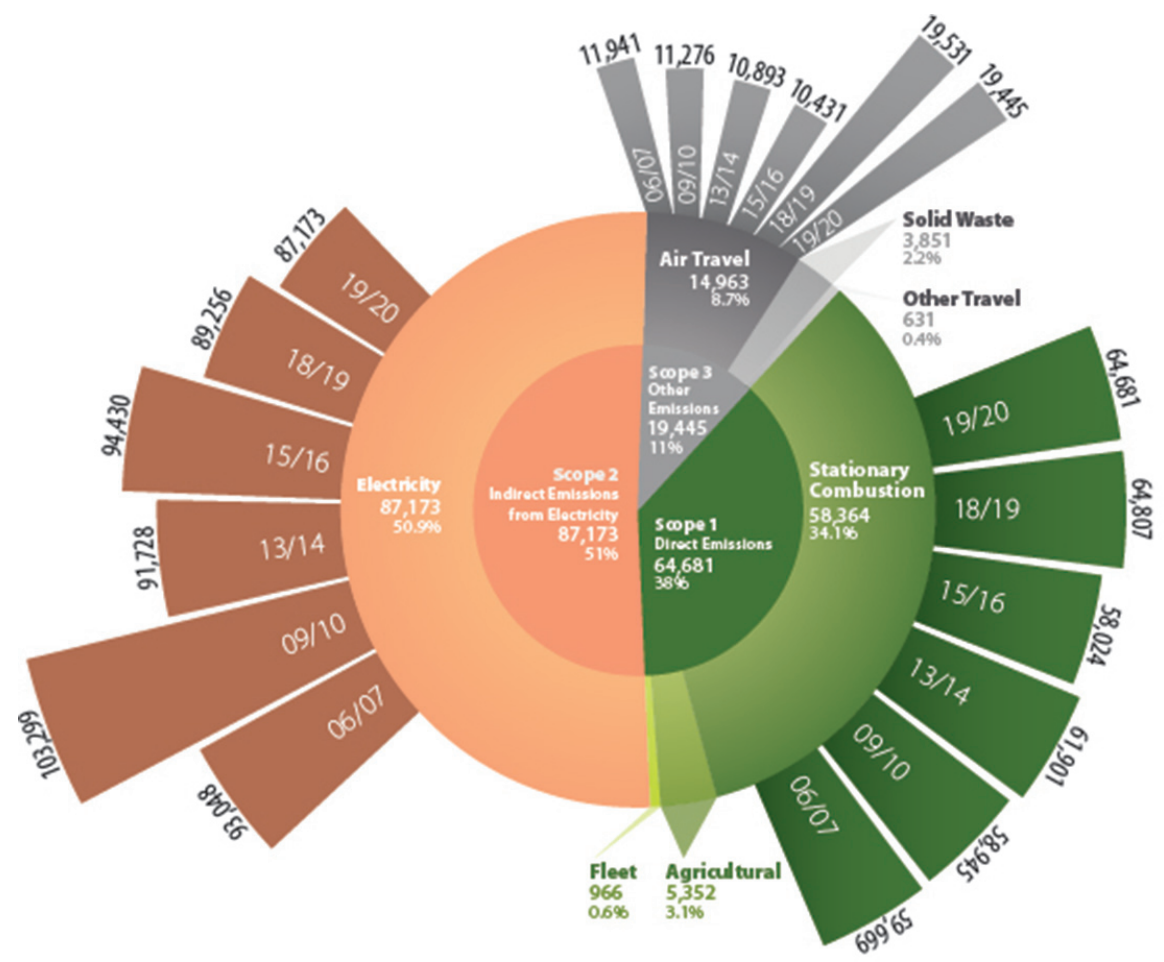

FIGURE 4.3 University of Saskatchewan's greenhouse gas reduction challenge for Scopes 1, 2, and $3\left(\mathrm{Mt} \mathrm{CO}_{2}-\mathrm{eq}\right)$ (Scope 4 greenhouse gas emissions not included) 
for building heating. While the intensity of natural gas use has varied over the years, when normalized for heating-degree-days it has shown a gradual $12.5 \%$ decline from baseline levels.

- Scope 2 emissions have decreased 6.3\% from the 2006/o7 baseline (as of $2019 / 20$ ) and constitute $51 \%$ of the university's measured emissions. These emissions are currently at the university's lowest reported level, despite an overall increase in university floor space.

- Scope 3 emissions have not been monitored. Recognizing them in full would greatly inflate the university's attributable emissions. To reduce them would require many diverse initiatives. Of the emissions in this scope that have been accounted for, air travel contributes significantly to the university's total emissions $(8.7 \%)$, with staff and faculty travelling a recorded 44.8 million kilometers in 2019/20. Full commuting emissions, as well as emissions associated with the university's purchasing and supply chains, are not currently accounted for.

- Avoided Scope 4 emissions have not been considered.

The University of Saskatchewan commits to reduce greenhouse gas emissions in keeping with the UN Intergovernmental Panel on Climate Change's science-based targets to limit global warming to 1.5 degrees $C$ above the pre-industrial norm. Our goal is to take bold steps to reduce our greenhouse gas emissions by $45 \%$ from our 2010 levels by 2030 by fostering an entrepreneurial campus spirit that utilizes the campus operations and community as a living laboratory to pilot both collaboratively developed climate change solutions and those solutions requiring coordinated local and regional efforts. This goal is ambitious - more ambitious than those of the City of Saskatoon and the Province of Saskatchewan, than the average of the top 15 research-intensive universities in Canada, and than of the federal government of Canada - and will require rapid and far-reaching changes. Systemic changes will be required to reduce the university's greenhouse gas emissions. The university will need to implement operational changes, and to make sure these changes do not stall, it will need to align institutional priorities, policies, programs, and services to achieve the reduction targets. To achieve this goal, we aim to:

- Seek further opportunities to divest from fossil fuels and to continue to engage in socially and environmentally responsible investing.

- Implement operational solutions to reduce our Scope 1, 2, and 3 emissions and to raise avoided Scope 4 emissions that we can avoid by working together at regional, local and international levels.

- Ensure that climate actions are bolstered and barriers removed by reviewing the university's strategic planning processes, decision-making 
processes, policies, and practices in order to confirm their alignment with the emission goals. Where needed, we will design new climate-sensitive policies that directly address reductions in Scope 1, Scope 2, and Scope 3 emissions. We will leverage our capital investments by working with governments, industries, and communities to increase the quantity of Scope 4 emissions we avoid.

- Map finance and accounting structures, norms, and practices (both capital and operations) to align with the emission goals. Improve our processes for allocating resources to revenue and support centers, making sure that they create the incentives and rewards required for effective climate action (for example, consider novel finance and accounting approaches to facilitate climate action such as piloting an internal carbon accounting strategy). Use a portion of budgetary savings from reduced emissions to advance climate action on campus and in the community.

- Ensure accountability and transparency in reporting on progress in achieving climate action goals. Design and implement more comprehensive measures of the university's emissions, make clear deadlines for on-campus climate action, and report annually to our governing bodies on progress toward achieving this commitment.

\subsection{Design Aspiration: Empower Action}

The challenge of mitigating and adapting to climate change represents a great opportunity for research-intensive universities to mobilize new forms of teaching and learning directed toward climate action.

Canada is uniquely situated to take advantage of this opportunity to re-examine how higher learning engages with students. More than half $(62 \%)$ of Canadians aged 25 to 64 have either college or university qualifications (OECD, 2019). The Canadian population is aging, however, and the rapid growth in the senior population $-16 \%$ of the country in 2014 and poised to grow to $23 \%$ by 2030 - creates a quickly expanding gap in the supply of educated young people, whom we will need to take on the novel challenges of the 21st century (Statistics Canada, 2015).

The Canadian population is also changing with respect to its Indigenous population (First Nations, Métis, or Inuk [Inuit]), which has grown by $43 \%$ since 2006, more than four times faster than the rest of the population (Statistics Canada, 2018), and which is becoming increasingly educated. In $2016,11 \%$ of Indigenous people overall aged 25 to 64 had a bachelor's degree or higher, up from $8 \%$ in 2006 , while those with a college diploma rose from $19 \%$ to $23 \%$ over the same time period (Statistics Canada, 2017). Increased university education in the Indigenous population brings increased opportunity to engage 
their traditionally educated elders and knowledge keepers, with their access to a thousand years of knowledge about the land, sky, and environment in their territories. Indigenous views on sustainability offer an indispensable advantage in addressing the climate crisis.

At the University of Saskatchewan, we are seeking new forms of teaching and learning that help students shift or reorder priorities - as to values (ways of relating to one another and the world), mindsets (forms of understanding), and skill sets (modes of action) (Kemmis et al., 2014) - so that they contribute to climate change mitigation and adaptation.

A shift in values is needed because societally we have become accustomed to living our lives based on values that are increasingly at odds with a sustainable planet (Hoffman, 2019). This shift is one of the most challenging to get to take root in society. It requires grassroots changes, formal changes (in rules and regulations), and informal changes (in norms). If we wish today's students to act on climate issues, we need them to gain the sort of learning experience that enables them to uncover and question their tacit perspectives and personal values (Shephard, 2008) and to develop the capacity to act individually, collectively, and in partnership with communities, governments, and industry.

A shift in mindsets is needed to empower people to devise disruptive (innovative and groundbreaking) solutions to climate change. This shift will require extending the modes of preparation beyond the purely cognitive and into the physical, emotional, and spiritual (Kemmis et al., 2014), a holistic pedagogical framework that has been known to, and practiced by, Indigenous peoples for centuries. Today's students need holistic teaching approaches (by which we mean extending beyond the cognitive to include ways of being) to help them understand the causes and consequences of climate change and their capacity for agency with respect to it.

To shift values and mindsets means also developing new forms of learning, ones that are personally relevant to students. It means giving students an action-oriented experience in place of the more traditional passive student role. Too often we educate in ways that are inclusive of large numbers but lack significance for individual learners. Today's students are looking to solve problems, to see and feel the real-life applications of their course work, and to develop the confidence and mastery they need to effect change after graduation.

We also need a shift in skill sets in order to equip all learners with those skills that are in high demand (Royal Bank of Canada, 2018). In particular, today's students need problem-solving skills, including critical thinking, analytics, math and numeracy, communication, collaboration, global competencies, 
and the ability to adapt and learn new things (Royal Bank of Canada, 2018). Problem-solving skills can be developed through involvement in creating and implementing climate solutions on campus, in our communities, and beyond. We also need to equip all learners with an understanding of ethics and activism, as well as the experience and ability to implement policy changes.

To shift values, mindsets, and skills effectively, we need to enable diverse learners to have access to what they need. To expand knowledge about climate change, we need to support both master learners (students who move forward at their own pace as they master knowledge and skills) and lifelong learners (students who learn continually throughout life, especially outside of, or after the completion of, formal schooling) (Crow \& Dabars, 2020). This conveying of "learning how to learn" is key in preparing students for an uncertain future, one likely marked with disruption and the need to pivot as circumstances change. Universities do not do well with this "learning how to learn", despite the centrality of this skill to student success post-graduation (Knight \& Yorke, 2003; Livingston, 2003). To facilitate development of this skill, universities could deviate from traditional degrees and offer alternative formats. For example, universities could allow master's degree candidates to "stack" several flexibly delivered modules. They could offer an accelerated bachelor's degree for those wishing to pivot to a new area of study after they complete an undergraduate program. They could offer credentials that are not a full degree, often called micro-credentials. Micro-credentials can be earned in short, bite-sized chunks. A micro-credential approach could provide an opportunity to engage students in all areas of study in climate education, and in formats that transcend disciplines. Other forms of skill validation, such as "badging", can facilitate students' finding, and engaging in, opportunities that develop essential skills in ways that are less restrictive than is a formal class. Micro-credential candidates can undertake relevant activities that align with their passions and, more practically, their schedules. They could find opportunities to do so either within or outside the formal curriculum, or both. In the assessment of skill development, measures could be broadened to include formal and informal educational experiences. In the efforts to nurture climate champions, such an increase in flexibility could act as an incentive as well as an acknowledgment.

Figure 4.4 plots the curriculum continuum against different modes of delivery (face-to-face to entirely online), demonstrating how combining various credential types with unique models for participation may open access for students with varied motivations and circumstances. The ability to access these alternative learning paths would need to be extended to all, an expansion that would require transformational changes to the structures of our institutions. 


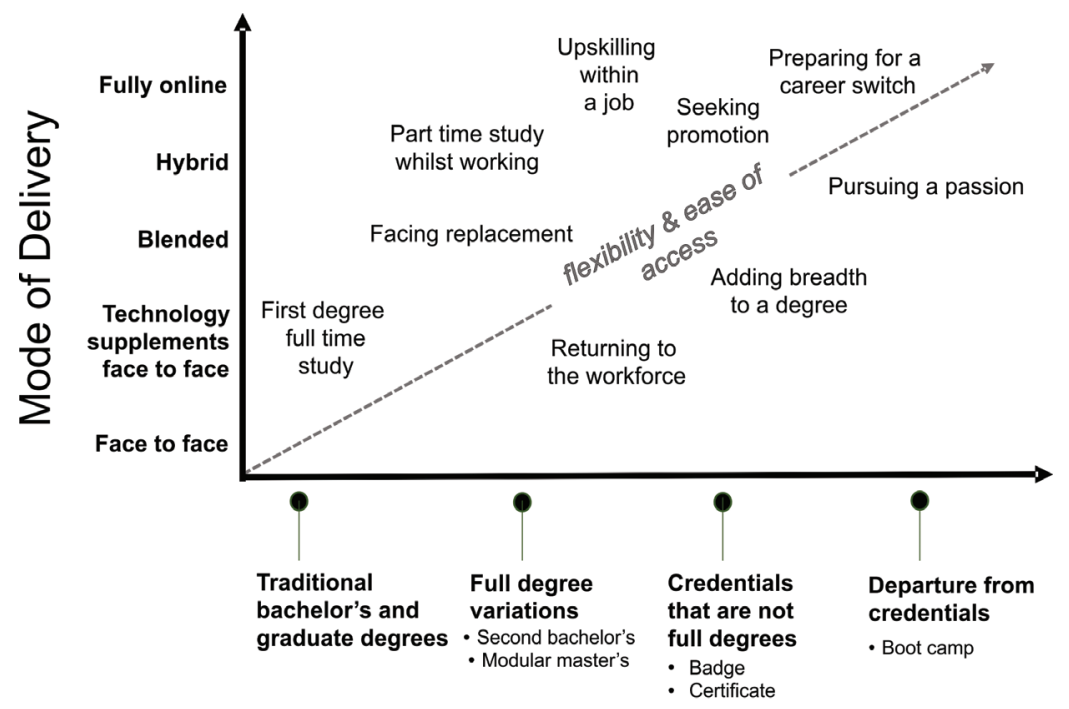

\section{Credential Continuum}

FIGURE 4.4 Plot of the credential continuum against the different modes of delivery that use varying levels of technology. Different student personas are inserted onto the created plot to indicate how different credentials and delivery models might open up access by increasing flexibility and ease of access

The University of Saskatchewan commits to creating a generation of learners and achievers focused on exploring and crafting innovative and workable solutions to the various aspects of climate change. Our goal is to ensure that every individual faculty member, staff member, and student has a holistic understanding of the need for climate action. In support of this goal, the entire institution will promote measures, enable participation, and get everyone engaged in exploring, discovering, and implementing new ideas. Specifically, we aim to:

- Equip faculty, staff, and students in all disciplines to be climate champions throughout their lives by ensuring that they have access to climate change educational experiences. To do so will require the university's mastering diverse bodies of knowledge about climate change and incorporating them into curricula across the campus.

- Develop mechanisms to engage faculty and academic units in changing or modifying their course and program curricula to advance climate literacy. Such mechanisms can accelerate the required shifts in values, mindsets, and skillsets and reduce the distance between where we are and where we need to be. 
- Give diverse learners access to climate change curricula, including enabling them to select their optimal mode of learning - in-person, synchronous, or asynchronous online - bearing in mind that all trainees will need access to the appropriate equipment. Additionally, do advance work on providing varied credential types so as to offer such learners increased flexibility and access.

- Enable all students to show local community leaders how climate change could affect their communities, and to create climate solutions through experiential learning programs involving projects, placements, and practicums, both within the institution and with the community.

\subsection{Design Aspiration: Capitalize on Strengths}

A key strength of any research-intensive university is its capacity for innovation. In the face of the 21st century challenges, the University of Saskatchewan needs to capitalize on its strengths and empower a "daring culture of creativity and innovation with the courage to confront humanity's greatest challenges and opportunities" (University of Saskatchewan, n.d.). Such a culture of innovation will "foster a problem-solving, entrepreneurial ethic among faculty, students, and staff, harnessing opportunities to apply our research, scholarly and artistic efforts" (University of Saskatchewan, n.d.). As a result, the university will co-create ideas and co-produce solutions within our communities. This innovative culture will focus on supporting people to create, diffuse, and scale more effective solutions to entrenched social problems (McConnell Foundation, n.d.).

The University of Saskatchewan has designated six signature areas in recognition of its existing and ongoing research into addressing the world's most pressing and challenging problems. For over a decade, these signature areas have shaped and guided institutional efforts and investments. Most important, these signature areas are not limited to a single discipline. Their relevance across the university - in the natural sciences, engineering, health sciences, social sciences, and humanities - has deepened the impact of the work locally, regionally, nationally, and internationally. Implicit in the choice of our signature areas is our understanding that meeting contemporary challenges must involve supporting a convergence of disciplines, whereby different disciplines cooperate to integrate their various bodies of knowledge, and whereby novel frameworks are formed to catalyze discovery and innovation, a "pinnacle of evolutionary integration across disciplines" (NSF, 2016).

The University of Saskatchewan will similarly achieve climate solutions through a whole-of-university response, creating opportunities for every 
instructor and researcher to explore the climate relevance of their work. For example, the university is recognized for its excellence in energy, food, and water security - that is, the adaptive capacity to safeguard the availability of, and access to, reliable and resilient energy, food, and water for human health and well-being. The university will seek out interactions among and between these signature research strengths and climate change (for example, how to enhance energy, food and water security in ways that enhance climate change mitigation and adaptation). Our convergent (coming-together-on-climate-change) response will include people in many roles. Instructors who create active learning environments. Discoverers working in use-inspired basic research. Entrepreneurs who can move discoveries into action. Artists who will translate discoveries into forms that inspire communities to act. Capacity builders who empower communities to act. Outstanding leaders capable of making national and global impacts. All knowledge thus attained will be put to work to reduce the risk of climate change in a just and equitable way for the benefit of society.

The University of Saskatchewan thus commits to creating and mobilizing new understandings, with a focus on innovative and workable ways to address and meet climate and other sustainability challenges. Our goal is to integrate learning, discovery, innovation, and entrepreneurship, and thereby put our knowledge to work to solve the problems presented by climate change. To achieve this goal, we aim to:

- Build leadership and capacity in innovation, encouraging every member to devote some of their energy toward a common project of addressing climate challenges.

- Create "convergent" innovation hubs, with the capacity not only to pilot and perfect technological innovations for solving local, regional, national, and global climate problems, but also to support and facilitate social innovations, such as the institutional changes that must accompany technological innovations.

- Forge and lead unique multi-community, multi-partner, and multi-sector collaborations to tackle the full spectrum of climate change mitigation and adaption challenges, from idea germination to translation into real-life approaches and solutions.

\subsection{Design Aspiration: Catalyze Social Change}

Confronting and tackling climate challenges requires cognizance of the local dimension of the problem as well as its global context. Universities can tap into the global pool of knowledge through global partnerships to spur climate innovation. This approach will require new forms of connecting spaces 
(forums), where competing world views can converge and a cooperative spirit can emerge that will create "new currents of thought that flow in different directions and overrun the old ways of thinking" (Ermine, 2007). This approach will also require new forms of, and an unprecedented level of, collaboration, in which the focus is on outcomes that benefit society and enhance society's capacity to act. Global dialogue will be an important tool for informing climate actions and translating lessons learned into policies, programs, and practices that can be disseminated and scaled up, enabling learning for all. By engaging in meaningful global dialogue, we can learn from one another, support each other, and chart a path for more ambitious action to tackle climate challenges.

The University of Saskatchewan commits itself to sharing knowledge, expertise, and experiences, and to effect the social change needed. By learning how to successfully meet climate challenges, we can share solutions that are capable of being broadly diffused and scaled up. Our goal is to inspire, and be agents of, "positive climate change" for the world. To achieve this goal, we aim to:

- Ensure that voices in our learning environments and in the research that we undertake are grounded in principles of equity, diversity, and inclusion.

- Engage in both local and global dialogue to develop a shared understanding of the challenges of, and solutions to, climate change.

- Leverage networks and partnerships between universities and the private sector, the public sector, not-for-profits, and civil society here and abroad to create collaborations that can harness opportunities for scalable social and technological climate solutions, and that can influence political leaders to accept and act on these solutions.

\section{4}

\section{Conclusion}

Universities have a pivotal role to play in the climate crisis, because they sit at the nexus of local, regional, national, and international cooperation and are positioned to contribute courageous leadership and inspiring thinking. To take on this role, however, universities must be willing to undergo a radical transformation. This means adopting responsive, flexible, and agile governance structures, becoming living laboratories that foster creative, innovative, and entrepreneurial campus spirit, and establishing diverse partnerships to implement coordinated climate action and climate solutions across all spheres of influence. Young people and young minds are perhaps the most powerful resources to meet the challenges associated with climate action. They need to be empowered through new methods of teaching and learning. Through 
combining the powerful resource of young people with the world-class researchers and facilities that universities can provide, and with government, industry, and community expertise and experience, the potential for meeting international action goals for the climate can be realized. This radical transformation will require unapologetic ambition and appropriate impatience as we move swiftly on climate action, paving a path toward a resilient future for universities and for the local and global communities in which they are embedded.

\section{Acknowledgments}

We thank Dr. Peter Stoicheff, President of the University of Saskatchewan, for his inspirational leadership that led to the pursuit of this work, and Dr. Chelsea Willness, University Secretary and Chief Governance Officer, for her insightful comments on this chapter.

\section{References}

Crow, M., \& Dabars, W. (2015). Designing the new American university. Johns Hopkins University Press.

Crow, M., \& Dabars, W. (2020). The fifth wave: The evolution of American higher education. Johns Hopkins University Press.

Ermine, W. (2007). The ethical space of engagement. Indigenous Law Journal, 6(1), 193203. https://jps.library.utoronto.ca/index.php/ilj/article/view/27669/2040o

Fuso, N., Sovaccol, B., Hughes, N., Cozzi, L., Costrave, E., Howells, M., ... Milligan, B. (2019). Connecting climate action with other sustainable development goals. Nature Sustainability, 2, 674-68o. https://doi.org/10.1038/s41893-019-0334-y

Government of Canada. (2017). National inventory report: Greenhouse gas sources and sinks in Canada, 1990-2017. http://www.publications.gc.ca/site/eng/9.506002/ publication.html

Government of Canada. (2019). Greenhouse gas and air pollutant emissions projections: 2019. https://www.canada.ca/en/environment-climate-change/services/climatechange/greenhouse-gas-emissions/projections/2019.html

Government of Canada. (2020). Progress towards Canada's greenhouse gas emissions reduction target. https://www.canada.ca/en/environment-climate-change/services/ environmental-indicators/progress-towards-canada-greenhouse-gas-emissionsreduction-target.html 
Government of Saskatchewan. (2020). 30 goals for 2030. https://www.saskatchewan.ca/ government/budget-planning-and-reporting/plan-for-growth/30-goals-for-2030

Hoffman, A. J. (2019, September 30). Climate change and our emerging cultural shift. Behavioral Scientist. https://behavioralscientist.org/climate-change-and-ouremerging-cultural-shift/

IPCC [Intergovernmental Panel on Climate Change]. (2018). Global warming of $1.5^{\circ} \mathrm{C}$. https://www.ipcc.ch/sri5/

Kemmis, S., Wilkinson, J., Edwards-Groves, C., Hardy, I., Grootenboer, P., \& Bristol, L. (2014). Changing practices, changing education. Springer.

Keys, P., Galaz, V., Dyer, M., Matthews, N., Folke, C., Nystrom, M., \& Conell, S. (2019). Anthropocene risk. Nature Sustainability, 2, 667-673. https://doi.org/10.1038/s41893o19-0327-X

Knight, P. T., \& Yorke, M. (2003). Assessment, learning and employability. Society for Research into Education \& Open University Press.

Livingston, J. (2003). Metacognition: An overview. US Department of Education. https://files.eric.ed.gov/fulltext/ED474273.pdf

McConnell Foundation. (n.d.). Social innovation. https://mcconnellfoundation.ca/ social-innovation-2/

NSF [National Science Foundation]. (2016). NSF's 10 big ideas, growing convergence research retrieved from national science foundations: Where discoveries begin. https://www.nsf.gov/news/special_reports/big_ideas/index.jsp

OECD. (2019). Education at a glance 2019: OECD indicators. https://doi.org/10.1787/ f8d788od-en

Ripple, W., Wolf, C., Newsome, T., Barnard, P., \& Moomaw, W. (2020). World scientists' warning of a climate emergency. Bioscience, 70(1), 8-12. https://doi.org/10.1093/ biosci.bizo88

Rockström, J., Steffen, W., Noone, K., Persson, A., Chapin III, F. S., Lambin, E. F., ... Foley, J. A. (2009). A safe operating space for humanity. Nature, 461, 472-475. https://doi.org/10.1038/461472a

Royal Bank of Canada. (2018). Humans wanted: How Canadian youth can thrive in the age of disruption. https://www.rbc.com/dms/enterprise/futurelaunch/humanswanted-how-canadian-youth-can-thrive-in-the-age-of-disruption.html

Shah, M. (2019, October 9). Climate change merges as one of the top ballot-box issues among voters: Ipsos poll. Global News. https://globalnews.ca/news/60o6868/ climate-change-federal-election-issue-poll/

Shephard, K. (2008). Higher education for sustainability: Seeking affective learning outcomes. International Journal of Sustainability in Higher Education, 9(1), 87-98. https://doi.org/10.1108/14676370810842201

Statistics Canada. (2015). Provincial/territorial distribution. Government of Canada. https://www150.statcan.gc.ca/n1/pub/89-645-x/20100o1/territorial-territoireeng.htm 
Statistics Canada. (2017). Education in Canada: Key results from the 2016 census. Government of Canada. https://www15o.statcan.gc.ca/n1/en/daily-quotidien/171129/ dq171129a-eng.pdf?st=pGRixsrv

Statistics Canada. (2018). First Nations people, Métis and Inuit in Canada: Diverse and growing populations. Government of Canada. https://www15o.statcan.gc.ca/n1/ pub/89-659-x/89-659-x2018oo1-eng.htm

Stechow, C., Minx, J., Riahi, K., Jewell, J., McCollum, D., Callaghan, M., \& Baiocchi, G. (2016). $2^{\circ} \mathrm{C}$ and SDGs: United they stand, divided they fall? Environmental Research Letters, 1-15. https://doi.org/10.1088/1748-9326/11/3/034022

Sustainable Canada Dialogues. (2015). Acting on climate change: Solutions from Canadian scholars. http://www.sustainablecanadadialogues.ca/files/PDF_DOCS/ SCD_short_3omarchlr.pdf

United Nations. (2015). Paris agreement. https://unfccc.int/sites/default/files/english_ paris_agreement.pdf

United Nations. (n.d.). Sustainable development goals. https://www.un.org/ sustainabledevelopment/sustainable-development-goals/

University of Saskatchewan. (n.d.). University plan 2025. https://plan.usask.ca/ courageous-curiosity.php

Walls, A. J. (2020, March 16). 8 principles for building a high-performance innovation team: On strategic agility and organizational design. Medium. https://medium.com/ swlh/8-principles-for-building-a-high-performance-innovation-team-f5911dd614do 